\title{
Survival and root structure changes of rice seedlings in different cultivars under submergence condition
}

\author{
DIAH RACHMAWATI ${ }^{1, \boldsymbol{v}}$, M.M. MARYANI ${ }^{2}$, SUHESTI KUSUMADEWI ${ }^{3}$, FITRI RAHAYU ${ }^{3}$ \\ ${ }^{1}$ Laboratory of Plant Physiology, Faculty of Biology, Universitas Gadjah Mada. Jl. Teknika Selatan, Sekip Utara, Sleman 55281, Yogyakarta, Indonesia. \\ Tel./fax.: +62-274-580839, "email: drachmawati@ugm.ac.id \\ ${ }^{2}$ Laboratory of Plant Structure and Development, Faculty of Biology, Universitas Gadjah Mada. Jl. Teknika Selatan, Sekip Utara, Sleman 55281, \\ Yogyakarta, Indonesia \\ ${ }^{3}$ Faculty of Biology, Universitas Gadjah Mada. Jl. Teknika Selatan, Sekip Utara, Sleman 55281, Yogyakarta, Indonesia
}

Manuscript received: 16 July 2019. Revision accepted: 22 September 2019.

\begin{abstract}
Rachmawati D, Maryani MM, Kusumadewi S, Rahayu F. 2019. Survival and root structure changes of rice seedlings in different cultivars under submergence condition. Biodiversitas 20:3011-3017. Submergence affects plant growth and fitness in natural and agricultural ecosystem. Plant survival to submergence is strongly influenced by the water level and duration of submergence. The objective of this study was to determine the survival, physiological and root anatomical changes of two rice cultivars seedlings to submergence The experiment used completely randomized design with three factors, cultivar (IR-64' and 'Inpara 5'), depth and duration of submergence. Depth of submergence consisted of 3 levels: without, partial and complete submergence. Fourteen days old seedlings were treated for 5, 10 and 15 days of submergence. The observed parameters were seedling survival, chlorophyll content, soluble sugar and starch content, plant biomass, and root anatomical structure. The results showed that seedlings survival of 'IR-64' and 'Inpara 5' decreased by increasing depth and duration of submergence. Increasing depth of submergence decreased chlorophyll content, soluble sugar content and plant biomass. Anatomically, depth and duration of submergence showed a greater increased in root cortex thickness, aerenchyma tissue diameter and the percentage of cortex to be aerenchyma of rice 'IR-64' and 'Inpara 5'. Fifteen days of complete submergence significantly decreased seedlings survival and increased the diameter of aerenchyma in both 'IR-64' and 'Inpara 5'.
\end{abstract}

Keywords: Aerenchyma, rice, root structure, submergence, survival

\section{INTRODUCTION}

Uncertain climate change causes the rice farming environment is not in accordance with expectations, such as the high rainfall that often causes excessive submergence at the early stage of rice development. Excess submergence can decrease rice growth and productivity. Rice plants require water for growth and development, but excessive water negatively affects their productivity and viability (Tejakhod et al. 2015). Changes in the duration and intensity of heavy rainfall cause flooding which is a serious stress for most crops. These conditions cause crops to be subjected to various water depth and the duration of flooding during their life cycle. Increased rainfall can lead to partial or complete submergence of plant resulting in $\mathrm{O}_{2}$ deficiency in the root or the entire plant (Voesenek and Bailey-Serres 2013). The severity of flooding relies on water excess circumstances varying from waterlogging or soil flooding (only root system immersed in watersaturated soil), partial waterlogging (partial flooding of the root system), submergence (the entire plant, root system, and above-ground shoot are underwater) and partial submergence (the entire root system and part of aboveground shoot are underwater) (Sasidharan et al. 2017).

Rice is a semi-aquatic plant generally tolerant to submergence, however, the excessive submergence causes impaired growth and development (Loreti et al. 2016; Upadhyay 2016). Rice plants exhibit escape or quiescence strategy in response to different types of submergence. Deepwater rice plants exhibit escape strategy by accelerating stem elongation to keep pace with the rising floodwater to escape complete submergence. Rapid stem elongation induced by submergence is essential for survival (Sakagami et al. 2009; Luo et al. 2011; Voesenek and Bailey-Serres 2013). The stem elongation response is modulated by the signaling of ethylene hormone (Upadhyay 2018). Submergence-tolerant rice plants have a quiescence strategy indicates by suppressing growth to preserve carbohydrate during submergence (Luo et al. 2011; Voesenek and Bailey-Serres 2013). Quiescence strategy can increase the tolerance of rice plants to submergence by maintaining high levels of carbohydrate storage coupled with minimum stem elongation and chlorophyll reduction (Sarkar et al. 1996; Fukao et al. 2006). Reduction stem elongation has a beneficial effect on the submergence tolerance in rice and is essential for survival under prolonged submergence (Setter and Laureles 1996; Voesenek and Bailey-Serres 2013).

Leaf chlorosis, growth inhibition, alterations in enzyme activities, lipid peroxidation membrane damage and death of the whole plant tissue are the characteristics of submergence effects in rice (Kawano et al. 2009; Jackson and Ram 2003). In addition, changes in soil physical and chemical properties due to flooding affect the ability of plants to withstand these conditions (Parent et al. 2008; Perata et al. 2011). The effect of submergence depends on 
genotype, development stage of the plant, the water level and duration of submergence and the degree of floodwater turbidity, light availability, temperature, humidity and status of carbohydrate (Das et al. 2005; Das et al. 2009).

Rice plants can withstand to submergence stress through the mechanism of avoidance and tolerance. Avoidance mechanism by enhancing shoot elongation in submergence conditions to cope with rising water levels. This mechanism helps increase the chance of survival of plants under submergence (Upadhyay 2016). Tolerance mechanism of rice plants to submergence include morphological, anatomical and metabolic changes that permit plants to survive without serious damage in response to anaerobic condition. An anaerobic condition due to submergence induces aerenchyma formation is important for tolerance and may enhance oxygen distribution to the root system (Parlanti et al. 2011; Phukan et al. 2016; Upadhyay 2016). According to Sauter (2013), submergence will increase the area of aerenchyma tissue on the root cortex to improve oxygen supply to the root. With the aerenchyma, oxygen can be easily transported from the roots to the stems underwater (Parlanti et al. 2011; Nishiuchi et al. 2012).

Carbohydrates have been recognized as an important factor in submergence-tolerant rice plants. Submergence tolerance is influenced by carbohydrate consumption during submerged (Setter and Laureles 1996). Panda and Sarkar (2014) stated that starch and total nonstructural carbohydrate (NSC) content is positively associated with survival percentage under submergence condition. Plant used the NSC to supply the required energy for survival (Das et al. 2005). Carbohydrate status was influenced by plant genotype, level of partial or complete submergence and floodwater environment (Das et al. 2009). Carbohydrate remaining after submergence will be especially important in recovery growth after submergence (Das et al. 2009; Kawano et al. 2009).

Submergence for varying depth and duration at the early stages resulted in decreasing growth and survivability. Submergence induces physiological and anatomical changes that vary among different rice cultivars (Das et al. 2005). 'Inpara 5' is 'IR-64' having submerged tolerant $\mathrm{Subl}$ gene known as rice tolerant to submergence during the vegetative phase of 14 days and have a shorter life cycle than other cultivars, while the 'IR-64' is widely cultivated in Indonesia, but not tolerant to submergence (Hairmansis et al. 2012). Based on that information, a laboratory experiment was conducted to determine the survival, physiological and root anatomical changes of rice (Oryza sativa L.) 'IR-64' and 'Inpara 5' at different water depth and duration of submergence.

\section{MATERIALS AND METHODS}

'IR-64', intolerant cultivar to submergence and 'Inpara 5', 'IR-64' having submerged tolerant $S u b 1$ gene were used as rice materials. The experiment was arranged in a completely randomized design with three factors including cultivars (IR64-intolerant and Inpara 5-tolerant), depth of submergence (without submergence (T0), partial submergence $\left(\mathrm{T}^{1} 12\right)$ and complete submergence (T1), and duration of submergence: 5 (L5), 10 (L10) and 15 (L15) days. Seeds of two rice (Oryza sativa L.) cultivars, 'IR-64' and 'Inpara 5' were incubated in water at about $28^{\circ} \mathrm{C}$ for three days. Germinated seeds of each cultivar were directly sown in pot containing a 2-kgs of soil. Rice seedlings were submerged at different water depth and duration in container and placed in the greenhouse. Each treatment consisted of 5 pots, containing 10 rice seedlings aged 14 days with an average seedling height of $20 \mathrm{~cm}$. At the time of treatment, water depth of partial submergence is $10 \mathrm{~cm}$ and complete submergence is $20 \mathrm{~cm}$ (seedlings are fully submerged) for duration 5, 10 and 15 days. Water depth of submergence was maintained by adding water every day. The water depth on complete submergence was maintained up to the seedlings were fully submerged. Water content in the treatment without submergence was maintained at field capacity condition. After submergence treatment, the rice growth was maintained at field capacity condition. During the experimental period, algal growth was minimized by removing them daily from the water surface using a small fishnet filter. Plant height after submergence treatment ranges from 24 to $29 \mathrm{~cm}$.

The parameters observed including plant survival, chlorophyll content, soluble sugar, and starch content, plant biomass, and root anatomical structure. Plant survival (\%) was recorded on $21^{\text {st }}$ day after the submergence treatment ended. Plant survival was determined by counting the number of plants that were able to produce at least one new leaf after submergence and was expressed as percentage of the initial number of plants before submergence. Dry weight of roots and shoots were weighed after pre-dried in an oven until reached constant weight.

Total chlorophyll content was determined colorimetrically following the procedure by Yoshida et al. (1976). Samples, the second fully expanded leaf from the tip was collected before desubmergence. Chopped fresh leaf tissue of $0.1 \mathrm{~g}$ was ground into fine powder and extracted using $80 \%$ acetone. The absorbance of extract was measured at 645 and $663 \mathrm{~nm}$ using a spectrophotometer (Genesis UVScanning Thermo-Scientific). Chlorophyll concentration were calculated using the formula $(17.32$ x A646 + $7.18 \mathrm{x}$ A663) mg. $\mathrm{L}^{-1}$. Chlorophyll content is expressed in $\mathrm{mg}$ chlorophyll per gram of fresh weight.

Soluble sugar and starch content of the shoot and root were estimated after 5, 10 and 15 days of submergence by anthrone method (Yoshida et al.1976). Briefly, for each measurement, shoot and root samples $(0.01 \mathrm{~g})$ were dried and ground to fine powder and extracted using $80 \%$ ethanol $(\mathrm{v} / \mathrm{v})(10 \mathrm{~mL})$. The extract was then used for soluble sugar analysis after the addition of anthrone reagent $(5 \mathrm{~mL})$, followed by a measurement of extract absorbance at 630 $\mathrm{nm}$ using a spectrophotometer. The remaining residue after soluble sugar extraction was dried and extracted using perchloric acid and then analyzed for starch (as glucose equivalent) using the anthrone reagent and a spectrophotometer (Genesis UV-Scanning Thermo-Scientific).

The statistical analysis was carried out for each parameter observed using ANOVA based on completely randomized design model SPSS software (version 22). The 
differences between means were compared by least significant difference (LSD) at $\mathrm{p}<0.05$.

\section{RESULTS AND DISCUSSION}

\section{Seedlings survival}

This study investigated the seedling survival of tolerant 'Inpara 5' and intolerant 'IR-64' rice cultivars in different depth and duration of submergence. The percentages of survived seedling at 21 days desubmergence are shown in Table 1. Early growth of rice plants are sensitive to submergence because of declining of $\mathrm{O}_{2}$ and $\mathrm{CO}_{2}$ availability, inhibited photosynthesis and respiration. The result showed that seedling survival of 'Inpara 5' and 'IR64' on complete submergence decreased considerably as increasing duration of submergence. Submergence reduced seedling survival of both cultivars with significantly greater effect on submergence-intolerant cultivar 'IR-64' than submergence-tolerant cultivar 'Inpara 5'. Submergence intolerant cultivar 'IR-64' showed lower survival percentage than the tolerant cultivar 'Inpara 5' at 21 days desubmergence. This finding is consistent with the result of Kato et al. (2014) that long-term partial submergence stress significantly reduced survival on intolerant rice cultivar (Rc18-Sub1 and Swarna-Sub1). The seedling survival of both cultivars substantially reduced and showed more dramatic effect on intolerant cultivar 'IR-64' whose survival reached $30 \%$ in complete submergence for 10 days. Intolerant cultivar showed greater responses to submergence than tolerant ones. The submergence intolerant rice cultivar developed visual damages, leaves turn yellow and the margins dry out under aerobic condition at desubmergence period.

Depth of submergence showed significant percentage of seedling survival decrease of 'IR-64' and 'Inpara 5' (Table 1). The seedlings survival in complete submergence is significantly lower than partial and without submergence. The percentage of survived seedling on partial submergence was similar to that without submergence. Decreasing seedling survival on complete submergence causes physical and chemical changes of soil such as declining soil redox potential and $\mathrm{pH}$ of the soil, reducing gas diffusion, increasing micronutrient concentration and accumulation of toxic compound (Parent et al. 2008; Perata et al. 2011; Huang et al. 2015). Changes in soil physicochemical properties due to limited oxygen in the submerged affect the ability of plants to survive (Parent et al. 2008).

Table 1. Percentage of seedling survival at 21 days desubmergence

\begin{tabular}{ccccc}
\hline \multirow{2}{*}{ Cultivars } & $\begin{array}{c}\text { Depth of } \\
\text { submergence }\end{array}$ & \multicolumn{2}{c}{ Duration of submergence (days) } \\
\cline { 3 - 5 } & T0 & L5 & L10 & L15 \\
\hline 'IR-64' & T1/2 & $84^{\mathrm{d}}$ & $80^{\mathrm{cd}}$ & $90^{\mathrm{cd}}$ \\
& $\mathrm{T} 1$ & $82^{\mathrm{cd}}$ & $30^{\mathrm{c}}$ & $88^{\mathrm{cd}}$ \\
& $\mathrm{T} 0$ & $84^{\mathrm{cd}}$ & $78^{\mathrm{cd}}$ & $80^{\mathrm{cd}}$ \\
'Inpara 5' & $\mathrm{T} 1 / 2$ & $90^{\mathrm{cd}}$ & $84^{\mathrm{cd}}$ & $90^{\mathrm{cd}}$ \\
& $\mathrm{T} 1$ & $80^{\mathrm{cd}}$ & $50^{\mathrm{b}}$ & $46^{\mathrm{ab}}$ \\
\hline
\end{tabular}

Means within the row and column followed by different letters differ significantly at $\mathrm{p}<0.05$ using least significant difference test
With complete submergence, the seedlings survival of both cultivars decreased considerably and this decrease became greater by increasing submergence depth and was substantially greater in 'IR-64' than 'Inpara 5'. The decreasing in seedling survival of 'IR-64's suggested that 'IR-64' is intolerant cultivar. In contrast to 'IR-64', 'Inpara 5 ' tends to survive optimally in partial submergence within 5,10 or 15 days. Seedling survival of this cultivar on partial submergence was greater than complete submergence or without submergence. This suggests that partial submergence might provide suitable condition for the growth of 'Inpara 5'. This result is consistent to results of Kato et al. (2014) and Vergara et al. (2014) that soilwaterlogging has minimum effect on rice plant in relation to survival and growth. Soil-waterlogging at 5-cm of depth has no effect on rice rather it is good but deleterious to other cereals.

In the partial submergence for duration 15 days, seedling survival of 'Inpara 5' rice cultivar reaches $90 \%$ up to 3 weeks of desubmergence. However, complete submergence for duration 10 and 15 days resulted in a decrease in tolerance as the recovery period. In this phase, the plants need water for the early growth, therefore, they will grow less optimal in submergence condition. Although water needs in vegetative phase are very important, but if the amount of water availability is in excess for the long term will cause adverse effects for plants. This condition resulted in tissue death, accumulation of metabolites reaching to toxic levels, reduction of chlorophyll content that will reduce photosynthesis and respiration that cause an energy deficiency. In this condition, plant growth will decline and eventually die (Singh et al. 2014; Huang et al. 2015).

\section{Physiological changes}

Chlorophyll is the component that may change in quantity due to the influence of external factors. Chlorophyll content after submergence was shown in Figure 1.

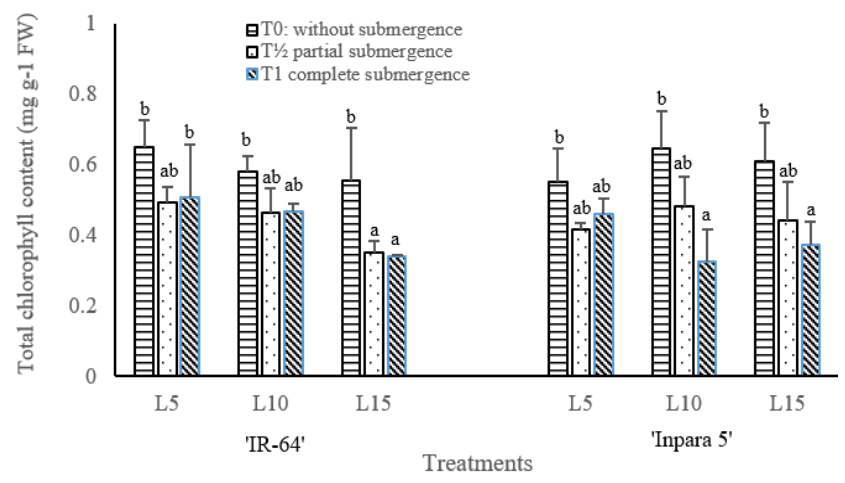

Figure 1. Total chlorophyll content ( $\mathrm{mg} \mathrm{g}^{-1}$ fresh weight) of rice cultivar 'IR-64' and 'Inpara 5' at different depth and duration of submergence. L5: 5 days of submergence, L10: ten days of submergence, and L15: fifteen days of submergence. Bars with the different letter are significantly different at $p<0.05$ using least significant difference test 
Leaf chlorophyll content was significantly affected by the depth of water level submergence. In both rice cultivars 'IR-64' and 'Inpara 5', chlorophyll content in partial and complete submergence was considerably lower than control (without submergence), but there was no difference between partial and complete submergence. Partial and complete of submergence considerably decreased chlorophyll content of both cultivars 'IR-64' and 'Inpara 5'. Compared to the control (without submergence), chlorophyll content of both cultivars decreased significantly after submergence and showed greater effect on 'Inpara 5'. Fifteen days of complete submergence caused greater reduction in leaf total chlorophyll content in 'Inpara 5'than in 'IR-64'. This is consistent with the report of Das et al. (2009) that submergence inhibits light penetration resulting in decreased chlorophyll levels. Low light intensity in rice significantly reduces plant biomass (Hairmansis et al. 2017). Decreasing of chlorophyll content during submergence is caused by ethylene that induces gene expression and enzyme activity of chlorophyllase (Sone and Sakagami 2017). Leaf chlorophyll is considerably decayed due to oxidative stress upon desubmergence (Kato et al. 2014). In addition, it can also be due to chlorophyll damage as a result of the submergence condition (Phukan et al. 2016; Sone and Sakagami 2017). This will result in decreasing photosynthetic rate which will have an effect on plant biomass.

In partial and complete submergence, soluble sugar content on 'IR-64' and 'Inpara 5' rice leaves decreased significantly (Table 2 ). The soluble sugar content in the partial and complete submergence treatment was lower than control (without submergence). Complete submergence reveals the lowest soluble sugar contents in all submergence treatment. This is likely because on complete submergence reduce chlorophyll content which causes the rate of photosynthesis to decrease.

The leaves are considered to be the primary location of photosynthesis. The decreased chlorophyll content of the leaves will reduce the rate of photosynthesis resulting in a reduction in sugar compound formation. Decreased levels of soluble sugars (sucrose, glucose, fructose) and starch due to increased depth and duration of submergence are caused by decreased photosynthesis. Decreased chlorophyll levels might be caused by chlorophyll degradation or decreased chlorophyll synthesis (Sone and Sakagami 2017). Chlorophyll is an important pigment that captures the energy of sunlight for photosynthesis. Moreover, submergence also inhibits the diffusion of $\mathrm{O}_{2}$ in order to

Tabel 2. Soluble sugar content ( $\mathrm{mg} \mathrm{g}^{-1}$ dry weight) of 'IR-64' and 'Inpara 5' rice leaves under submergence condition

\begin{tabular}{lcccc}
\hline \multirow{2}{*}{ Cultivars } & $\begin{array}{c}\text { Depth of } \\
\text { submergence }\end{array}$ & \multicolumn{3}{c}{ Duration of submergence } \\
\cline { 3 - 5 } & $\mathrm{T} 0$ & $0.314^{\mathrm{d}}$ & $\mathbf{L 1 0}$ & $\mathbf{L 1 5}$ \\
\hline 'IR-64' & $\mathrm{T} 1 / 2$ & $0.206^{\mathrm{c}}$ & $0.247^{\mathrm{cd}}$ \\
& $\mathrm{T} 1$ & $0.131^{\mathrm{b}}$ & $0.123^{\mathrm{b}}$ & $0.266^{\mathrm{cd}}$ \\
& $\mathrm{T} 0.127^{\mathrm{b}}$ \\
'Inpara 5' & $\mathrm{T} 1$ & $0.225^{\mathrm{c}}$ & $0.186^{\mathrm{bc}}$ & $0.215^{\mathrm{c}}$ \\
& $\mathrm{T} 1 / 2$ & $0.245^{\mathrm{cd}}$ & $0.083^{\mathrm{a}}$ & $0.096^{\mathrm{a}}$ \\
& $\mathrm{T} 1$ & $0.128^{\mathrm{b}}$ & $0.116^{\mathrm{b}}$ & $0.086^{\mathrm{a}}$ \\
\hline
\end{tabular}

Means within the row and column followed by different letters differ significantly at $\mathrm{p}<0.05$ using least significant difference test prevent plant for doing aerobic respiration (Jackson and Ram 2003; Sauter 2013; Kato et al. 2014).

Pourabdal et al. (2008) state that increasing the submergence period will gradually reduce the amount of soluble sugar. This is consistent with the results of this study that dissolved sugar levels tend to decline with the longer submergence period. The length of the submergence period also affects the soluble sugar content in 'IR-64' and 'Inpara 5'. Sarkar et al. (1996) reported that the seedlings of the tolerant species contain $20-30 \%$ more starch than those of the intolerant varieties. The soluble sugar content in partial and complete submergence decreases with submergence. These starch reserves were rapidly used up on the submergence. During submergence, Swarna accelerated the rate of stem and leaf elongation and rapidly consumed nonstructural carbohydrate (NSC). In contrast, Swarna Sub1 consumed energy resources more slowly and maintained similar growth rate to that of non-submerged plants (Panda and Sarkar 2012).

Starch content of 'IR-64' is increased in the partial and complete submergence treatment (Table 3). Increased starch content in the rice leaves during submergence is an effort to save energy and grow after submergence (Das et al. 2005). The results indicated that submergence caused an increase in starch content in leaves as energy storage. However, starch content of 'Inpara 5' in the partial and complete submergence was lower than control. This is probably because the starch is broken down into simple sugars in response to submergence. Non-structural carbohydrates, in the case of starch and soluble sugars, are an important factor in restoring energy to maintain metabolic processes during submergence, to increase regeneration and to recover seedling after submergence (Das et al. 2005). Pourabdal et al. (2008) suggested that increasing the duration of submergence decreased the levels of soluble sugars in roots and shoot of maize. The decrease in carbohydrate content was positively correlated with decreased levels of chlorophyll because glucose is the product of the photosynthesis process. Decreasing of soluble sugars and starch contents in line with increasing depth and length of submergence caused by the decrease of photosynthesis are likely due to reduced synthesis or increased degradation of chlorophyll. It is closely related to chlorophyll which is important to capture energy from sunlight for photosynthesis. In addition, submergence delays $\mathrm{O}_{2}$ diffusion and inhibition of aerobic respiration which then results in deficient of energy (Abiko et al. 2012; Sauter 2013).

Tabel 3. Starch content ( $m g \mathrm{~g}^{-1}$ dry weight) of 'IR-64' and 'Inpara 5' rice leaves under submergence condition

\begin{tabular}{lcccc}
\multirow{2}{*}{ Cultivars } & $\begin{array}{c}\text { Depth of } \\
\text { submergence }\end{array}$ & \multicolumn{3}{c}{ Duration of submergence } \\
\cline { 2 - 5 } & T0 & $1.662^{\mathrm{ab}}$ & $1.183^{\mathrm{a}}$ & $4.799^{\mathrm{cd}}$ \\
\hline 'IR-64' & $\mathrm{T} 1 / 2$ & $1.904^{\mathrm{ab}}$ & $4.891^{\mathrm{cd}}$ & $4.220^{\mathrm{bc}}$ \\
& $\mathrm{T} 1$ & $3.250^{\mathrm{b}}$ & $5.157^{\mathrm{de}}$ & $4.423^{\mathrm{bc}}$ \\
& $\mathrm{T} 0$ & $6.986^{\mathrm{ef}}$ & $4.895^{\mathrm{cd}}$ & $7.998^{\mathrm{f}}$ \\
'Inpara 5' & $\mathrm{T} 1 / 2$ & $5.870^{\mathrm{de}}$ & $4.574^{\mathrm{bc}}$ & $1.376^{\mathrm{a}}$ \\
& $\mathrm{T} 1$ & $5.794^{\mathrm{de}}$ & $3.771^{\mathrm{b}}$ & $4.812^{\mathrm{cd}}$ \\
\hline
\end{tabular}

Means within the row and column followed by different letters differ significantly at $\mathrm{p}<0.05$ using least significant difference test 
Table 4. Dry weight of shoots (g/plant) of rice cultivar 'IR-64' and 'Inpara 5' under submergence condition

\begin{tabular}{lcccc}
\hline \multirow{2}{*}{ Cultivars } & Depth of & \multicolumn{3}{c}{ Duration of submergence } \\
\cline { 2 - 5 } & submergence & L5 & \multicolumn{1}{c}{ L10 } & L15 \\
\hline 'IR-64' & $\mathrm{T} 0$ & $0.0155^{\mathrm{abcd}}$ & $0.0211^{\mathrm{e}}$ & $0.0213^{\mathrm{e}}$ \\
& $\mathrm{T} \mathrm{1} / 2$ & $0.0154^{\mathrm{abcd}}$ & $0.0149^{\mathrm{abcd}}$ & $0.0157^{\mathrm{abcd}}$ \\
& $\mathrm{T} 1$ & $0.0113^{\mathrm{ab}}$ & $0.0137^{\mathrm{abcd}}$ & $0.0162^{\mathrm{bcd}}$ \\
'Inpara 5' & $\mathrm{T} 0$ & $0.0145^{\mathrm{abc}}$ & $0.0172^{\mathrm{cde}}$ & $0.0184^{\mathrm{de}}$ \\
& $\mathrm{T} 1 / 2$ & $0.0132^{\mathrm{abc}}$ & $0.0129^{\mathrm{abc}}$ & $0.0176^{\mathrm{cde}}$ \\
& $\mathrm{T} 1$ & $0.0108^{\mathrm{a}}$ & $0.0110^{\mathrm{a}}$ & $0.0109^{\mathrm{a}}$ \\
\hline
\end{tabular}

Means within the row and column followed by different letters differ significantly at $p<0.05$ using least significant difference test
Table 5. Dry weight of roots (g/plant) of rice cultivar 'IR-64' and 'Inpara 5' under submergence condition

\begin{tabular}{lcccc}
\hline \multirow{2}{*}{ Cultivars } & Depth of & \multicolumn{3}{c}{ Duration of submergence } \\
\cline { 3 - 5 } & submergence & L5 & L10 & L15 \\
\hline 'IR-64' & $\mathrm{T} 0$ & $0.0039^{\mathrm{b}}$ & $0.0027^{\mathrm{a}}$ & $0.0028^{\mathrm{ab}}$ \\
& $\mathrm{T} 1 / 2$ & $0.0026^{\mathrm{a}}$ & $0.0021^{\mathrm{a}}$ & $0.0026^{\mathrm{a}}$ \\
& $\mathrm{T} 1$ & $0.0021^{\mathrm{a}}$ & $0.0021^{\mathrm{a}}$ & $0.0019^{\mathrm{a}}$ \\
'Inpara 5' & $\mathrm{T} 0$ & $0.0023^{\mathrm{a}}$ & $0.0022^{\mathrm{a}}$ & $0.0022^{\mathrm{a}}$ \\
& $\mathrm{T} 1 / 2$ & $0.0027^{\mathrm{a}}$ & $0.0022^{\mathrm{a}}$ & $0.0026^{\mathrm{a}}$ \\
& $\mathrm{T} 1$ & $0.0024^{\mathrm{a}}$ & $0.0020^{\mathrm{a}}$ & $0.0016^{\mathrm{a}}$ \\
\hline
\end{tabular}

Means within the row and column followed by different letters differ significantly at $p<0.05$ using least significant difference test
The treatment without submergence in 'IR-64' starch content increase in line the increasing of submergence duration. However, in complete submergence, the starch content was higher than in partial submergence. This is probably due to the plant's ability to extend the leaves when it is submerged. In complete submergence, shoot of 'IR-64' is able to penetrate the water surface. This will affect its capacity to perform photosynthesis. It appears that there is a significant impact on starch levels in the long submergence period. The longer the duration of submergence indicates the higher starch content.

Submergence influences plant biomass is represented by dry weight of roots and shoots. Plant biomass is net photosynthesis that will be used as carbon skeleton of primary organic compound (sugar, protein, lipid and nucleic acid) and other organic compounds and the rest will be stored as storage food. Roots and shoots dry weight of both cultivars 'IR-64' and 'Inpara 5' were decreased by increasing the depth of submergence (Tables 4 and 5). Decreasing biomass in 'IR-64' was higher than 'Inpara 5'. This is consistent to report of Singh et al. (2014) that the rice lines without SUBI showed greater reduction of biomass on submerged condition.

The findings showed that dry weight of shoots and roots on both 'IR-64' and 'Inpara 5' cultivars decreased in the partial and complete submergence. This is likely due to a reduction of oxygen supply in submerged plant organs. Submergence creates changes in soil physical and chemical properties and affects the ability of plants to survive in these circumstances (Perata et al. 2011). Kumar et al (2007) reported that biomass may or may not decrease under stagnant flooding, while under submergence above ground biomass decrease owing to photosynthetic system impairment. Moreover, the decrease in shoot dry weight may be triggered by obstruction of light penetration and air diffusion when submerged, which will reduce photosynthesis. Biomass reduction due to decreased light interception and leaf growth above the water (Kato et al. 2014).

\section{Root anatomical changes}

Depth of submergence significantly increased root cortical thickness (CT) in both 'IR-64' and 'Inpara 5' and this is more detected in L5 and L10 (Table 6). This is consistent with the results of Bianchini et al. (2000) that submergence treatment increased cortical thickness of Chorisia speciosa caused by more cells number and larger cell size. The percentage of cortex cells to be aerenchyma (PA) in those two cultivars also increased compared to control. Duration of submergence alone did not effect on both CT and PA of 'IR-64'. In contrast to the 'IR-64', 'Inpara 5' has smaller change on PA, indicating this cultivar performs tolerance character to submergence. The cortex is a network that plays an important role in the diffusion of $\mathrm{O}_{2}$ and other gases in the flooding since most of the cortical parenchyma cells will develop into aerenchyma (Pramanik et al. 2016). This is consistent with the results obtained in this study that the longer and deeper of submergence, the thicker of cortical tissue and the bigger aerenchyma size developed. The formation of aerenchyma has an adaptation mechanism to prevent the loss of oxygen in the submerged organs (De Souza et al. 2009; Parlanti et al. 2011; Sauter 2013). The formation of aerenchyma in the root cortex can be used as an anatomical adaptation strategy to avoid the impact of submergence by allowing aeration of submerged organs (Nishiuchi et al. 2012; Voesenek and Bailey-Serres 2013). The rearrangement of cortical cells to a greater increase in the space between cells leads to increase in the diffusion of $\mathrm{O}_{2}$ to the roots (Bianchini et al. 2000).

Furthermore, depth and duration of submergence significantly increased the aerenchyma tissues diameter (AD) of 'IR-64' and 'Inpara 5' (Table 7). The deeper and longer of submergence showed the greater the diameter of aerenchyma. Root tissue aerenchyma diameter of the 'IR64' increased gradually in line with the submergence level, while at 'Inpara 5', root aerenchyma tissue diameter on partial submergence was the same as the control (without submergence) and increased significantly in completely submergence roots (Table 7). From Table 7 can also be seen that the diameter of aerenchyma tend to be the same between those two cultivars, 'IR 64" and 'Inpara 5' in complete submergence for both 10 and 15 days submergence treatments. Enhancing the formation of aerenchyma is intended to improve oxygen supply during submergence, facilitates transport of oxygen and other gases from the roots to the stems underwater (Sauter 2013). 
Table 6. Root cortex thickness $(\mathrm{CT} ; \mu \mathrm{m})$ and the percentage of cortex to be aerenchyma (PA) of rice cultivar 'IR-64' and 'Inpara 5' under submergence condition

\begin{tabular}{|c|c|c|c|c|c|c|c|}
\hline \multirow{3}{*}{ Cultivars } & \multirow{3}{*}{$\begin{array}{c}\text { Depth of } \\
\text { submergence }\end{array}$} & \multicolumn{6}{|c|}{ Duration of submergence } \\
\hline & & \multicolumn{2}{|c|}{ L5 } & \multicolumn{2}{|c|}{ L10 } & \multicolumn{2}{|c|}{ L15 } \\
\hline & & CT & $\mathbf{P A}$ & CT & PA & CT & $\mathbf{P A}$ \\
\hline \multirow[t]{3}{*}{ 'IR-64' } & T0 & $82.46^{\mathrm{a}}$ & $81^{\mathrm{a}}$ & $266.28^{\mathrm{cd}}$ & $85^{\mathrm{ab}}$ & $247.90^{\mathrm{bc}}$ & $98^{c}$ \\
\hline & $T^{1 / 2}$ & $159.88^{b}$ & $99^{c}$ & $238.03^{b c}$ & $97^{c}$ & $239.33^{\mathrm{bc}}$ & $100^{c}$ \\
\hline & $\mathrm{T} 1$ & $300.73^{\mathrm{cd}}$ & $100^{c}$ & $329.74^{\mathrm{d}}$ & $98^{c}$ & $328.89^{d}$ & $100^{c}$ \\
\hline \multirow[t]{3}{*}{ 'Inpara 5' } & T0 & $154.14^{\mathrm{b}}$ & $93^{b c}$ & $298.16^{\mathrm{cd}}$ & $94^{\mathrm{bc}}$ & $179.52^{\mathrm{bc}}$ & $85^{\mathrm{ab}}$ \\
\hline & $T^{1 / 2}$ & $268.22^{\mathrm{cd}}$ & 93 bc & $260.33^{\mathrm{cd}}$ & $96^{\mathrm{bc}}$ & $338.29^{d}$ & $78^{\mathrm{a}}$ \\
\hline & $\mathrm{T} 1$ & $268.01^{\mathrm{cd}}$ & $97^{\mathrm{c}}$ & $341.20^{\mathrm{d}}$ & $100^{\mathrm{a}}$ & $320.72^{\mathrm{d}}$ & $100^{c}$ \\
\hline
\end{tabular}

Means of each parameter within the row and column followed by different letters differ significantly at $p<0.05$ using least significant difference test

Tabel 7. Roots aerenchyma tissues diameter $(\mathrm{AD} ; \mu \mathrm{m})$ of rice cultivar 'IR-64' and 'Inpara 5' under submergence condition

\begin{tabular}{lcccc}
\hline \multirow{2}{*}{ Cultivars } & $\begin{array}{c}\text { Depth of } \\
\text { submergence }\end{array}$ & \multicolumn{3}{c}{ Duration of submergence } \\
\cline { 3 - 5 } & $\mathrm{T} 0$ & $81.40^{\mathrm{a}}$ & $227.22^{\mathrm{cd}}$ & $262.84^{\mathrm{de}}$ \\
& $\mathrm{T} 1 / 2$ & $134.81^{\mathrm{b}}$ & $283.11^{\mathrm{ef}}$ & $303.83^{\mathrm{fg}}$ \\
& $\mathrm{T} 1$ & $216.99^{\mathrm{c}}$ & $257,28^{\mathrm{de}}$ & $341.92^{\mathrm{g}}$ \\
'IR-64' & & & & \\
& $\mathrm{T} 0$ & $110.88^{\mathrm{ab}}$ & $253.21^{\mathrm{d}}$ & $192.93^{\mathrm{bc}}$ \\
& $\mathrm{T}$ 1/2 & $221.61^{\mathrm{cd}}$ & $178.17^{\mathrm{b}}$ & $165.66^{\mathrm{b}}$ \\
& $\mathrm{T} 1$ & $242.67^{\mathrm{d}}$ & $247.41^{\mathrm{d}}$ & $293.29^{\mathrm{fg}}$ \\
\hline
\end{tabular}

Means within the row and column followed by different letters differ significantly at $\mathrm{p}<0.05$ using least significant difference test

Fully developed aerenchyma observed in complete submergence roots (Table 6) for both cultivars, separates the inner-stele from the outer cell layers (exodermis, and epidermis). Strands forming radial bridges from remaining cells in the cortex are important for the structural integrity of the root and for nutrients transport. The epidermis, hypodermis/exodermis, endodermis, and stele of roots from both cultivars remain intact and are unaffected. It was suggested that aerenchyma in rice roots occur under lysigenous formation (Shiono et al. 2008) where cortical cell walls are lysis and this evidence does not bring any damage to other cells. Tolerant cultivars produce larger aerenchyma tissue in root during submergence (Pramanik et al. 2016). In response to submergence, aerenchyma formed in the tolerant plants is more extensive than in intolerant ones (Colmer and Voesenek 2009; Abiko et al. 2012). Aerenchyma might provide photosynthesis benefit to transport $\mathrm{CO}_{2}$ from root respiration and bring it to the leaf intercellular spaces.

From this research, it can be obtained information that seedlings survival of 'IR-64' and 'Inpara 5' decreased by increasing depth and duration of submergence. Intolerant cultivar 'IR-64' showed lower survival percentage than the tolerant cultivar 'Inpara 5'. 'Inpara 5' has a greater survival because it has a subl gene as rice tolerant to submergence during the vegetative phase of 14 days. Depth and duration of submergence significantly increased the root cortex thickness and aerenchyma tissues diameter of 'IR64' and 'Inpara 5'. 'Inpara 5' has smaller change on the percentage of cortex cells to be aerenchyma, suggesting this cultivar performs tolerance character to submergence. Increased root cortex thickness, percentage of cortex cells to be aerenchyma and aerenchyma tissue diameter indicated the rice tolerance against submergence.

\section{REFERENCES}

Abiko T, Kotula L, Shiono K, Malik AI, Colmer TD, Nakazono M. 2012. Enhanced formation of aerenchyma and induction of a barrier to radial oxygen loss in adventitious roots of Zea nicaraguensis contribute to its waterlogging tolerance as compared with maize (Zea mays ssp. mays). Plant Cell Environ 35: 1618-1630.

Bianchini E, Medri ME, Pimeta JA, Giloni PC, Kolb RM, Correa GT. 2000. Anatomical alternation in plants of Chorisia speciosa A. St. Hill submitted to flooding. Interciencia 25 (9): 436-441.

Colmer TD, Voesenek LAC. 2009. Flooding tolerance: suites of plant traits in variable environments. Funct Plant Biol 36: 665-681.

Das KK, Sarkar RK, Ismail AM. 2005. Elongation ability and nonstructural carbohydrate levels in relation to submergence tolerance in rice. Plant Sci 16 (8): 131-136.

Das KK, Panda D, Sarkar RK, Reddy JN, Ismail AM. 2009. Submergence tolerance in relation to variable floodwater conditions in rice. Environ Exp Bot 66: 425-434.

De Souza TC, de Castro EM, Pereira EJ, Parentoni SN, Magalhaens PC. 2009. Morpho-anatomical characterization of root reccurent selection cycles for flood tolerance of maize (Zea mays L.). Plant Soil Environ 55 (11): 504-510.

Fukao T, Xu K, Ronald PC, Bailey-Serres J. 2006. A variable cluster of ethylene response factor-like genes regulates metabolic and development acclimation responses to submergence in rice. Plant Cell 18: 2021-2034.

Hairmansis A, Supartopo, Kustianto B, Suwarno, Pane H. 2012. Perakitan dan pengembangan kultivar unggul karu padi toleran rendaman air INPARA 4 dan INPARA 5 untuk daerah rawan banjir. Jurnal Litbang Pertanian 31 (1): 1-7. [Indonesian]

Hairmansis A, Yullianida, Supartopo, Jamil A, Suwarno. 2017. Variability of upland rice genotypes response to low light intensity. Biodiversitas 18 (3): 1122-1129. [Indonesian]

Huang X, Shabala S, Shabala L. 2015. Linking waterlogging tolerance with $\mathrm{Mn}^{2+}$ toxicity: a case study for barley. Plant Biol (Stuttg) 17: 2633.

Jackson MB, Ram PC. 2003. Physiological and molecular basis of susceptible and tolerance of rice plant to complete submergence. Ann Bot 91: 227-241.

Kato Y, Collard BCY, Septiningsih EM, Ismail AM. 2014. Physiological analyses of traits associated with tolerance of long-term partial submergence in rice. AoB Plant 6: plu058. DOI: 10.1093/aobpla/plu058.

Kumar SR, Ray A, Sethi SK, Chattopadhyay K. 2017. Physiological Basis of Stagnant Flooding Tolerance in Rice. Rice Sci 24 (2): 73-84. 
Kawano N, Ito O, Sakagami J. 2009. Morphological and physiologica responses of rice seedlings to complete submergence (flash flooding). Ann Bot 103 (2): 161-169.

Loreti E, van Veen H, Perata P. 2016. Plant responses to flooding stress Curr Opin Plant Biol 33: 64-71.

Luo F, Nagel KA, Scharr H, Zeng B, Schurr U, Matsubara S. 2011. Recovery dynamics of growth, photosynthesis and carbohydrate accumulation after de-submergence: a comparison between two wetland plants showing escape and quiescence strategies. Ann Bot 107: 49-63.

Nio SA, Siahaan R, Ludon DPM. 2019. Partial submergence tolerance in rice (Oryza sativa $\mathrm{L}$ ) cultivated in North Sulawesi at vegetative phase. Pak J Biol Sci 22: 95-102.

Nishiuchi S, Yamauchi T, Takahashi H, Kotula L, Nakazono M. 2012. Mechanisms for coping with submergence and waterlogging in rice. Rice 5: 2-14.

Panda D, Sarkar RK. 2012. Role of non-structural carbohydrate and its catabolism associated with Sub1 QTL in rice subjected to complete submergence. Exp Agric 48 (4): 502-512.

Panda D, Sarkar RK. 2014. Mechanism associated with nonstructural carbohydrate accumulation in submergence tolerant rice (Oryza sativa L. ) cultivars. J Plant Interact 9 (1): 62-68.

Parent C, Nicolas C, Audrey B, Michele C, James FD. 2008. An overview of plant responses to soil waterlogging. Plant Stress 2 (1): 20-27.

Parlanti S, Kudahettige NP, Lombardi L, Mensuali-Sodi A, Alpi A, Perata P, Pucciariello C. 2011. Distinct mechanisms for aerenchyma formation in leaf sheaths of rice genotypes displaying a quiescence or escape strategy for flooding tolerance. Ann Bot 107: 1335-1343.

Perata P, Amstrong W, Voesenek LACJ. 2011. Plant and flooding stress. New Phytol 190: 269-273.

Phukan UJ, Mishra S, Shukla RK. 2016. Waterlogging and submergence stress: affects and acclimation. Crit Rev Biotechnol 36 (5): 956-966.

Pourabdal I, Heidary R, Farboodnia T. 2008. Effects of three differen flooding periods on some anatomical, morphological and biochemical changings in maize (Zea mays L.) seedlings. Asian J Plant Sci 7: 90 94.

Pramanik MHR, Shelley IJ, Adhikary D, Islam MO. 2016. Carbohydrate reserve and aerenchyma formation enhance submergence tolerance in rice. Prog Agric 27 (3): 256-264.
Sauter M. 2013. Root responses to flooding. Curr Opin Plant Biol 16: 282286.

Sakagami JI, Joho Y, Ito O. 2009. Contrasting physiological responses by cultivars of Oryza sativa and $O$. glaberrima to prolonged submergence. Ann Bot 103: 171-180.

Sarkar RK, De RN, Reddy JN, Ramakrishnaya G. 1996. Studies on the submergence tolerance mechanism in relation to carbohydrate, chlorophyll and specific leaf weight in rice (Oryza sativa L.). J Plant Physiol 149: 623-625.

Sasidharan RJ, Bailey-Serres J, Ashikari M, Atewll BJ, Colmer TD et al. 2017. Community recommendation on terminology and procedures used in flooding and low oxygen stress research. New Phytol 214: 1403-1407.

Setter T, Laureles E. 1996. The beneficial effect of reduced elongation growth on submergence tolerance of rice. J Exp Bot 47: 1551-1559.

Shiono K, Takahashi H, Colmer TD, Nakazono M. 2008. Role of ethylene in acclimations to promote oxygen transport in roots of plants in waterlogged soils. Plant Sci 175: 52-58.

Singh S, Mackill DJ, Ismail AM. 2014. Physiological basis of tolerance to complete submergence in rice involves genetic factors in addition to the SUB1 gene. AoB Plants 6: 1-20.

Sone C, Sakagami J. 2017. Physiological mechanism of chlorophyll breakdown for leaves under complete submergence in rice. Crop Sci 57 (5): 2729-2738.

Tejakhod S, Ellis RH, Hammond JP. 2015. The Effect of Submergence on rice seed quality. Proc Environ Sci 29: 139. DOI: 10.1016/j.proenv.2015.07.227.

Upadhyay RK. 2016. How rice (Oryza sativa L.), a semi-aquatic plant adapt to natural flood or submerged condition? A physiological perspective. Sains Malaysiana 45 (6): 879-882.

Upadhyay RK. 2018. Oxidative injury and its detoxification in rice plants after submergence stress. Proc Natl Acad Sci India 88 (1): 15-21.

Vergara GV, Nugraha Y, Esguerra MQ, Mackill DJ. 2014. Variation in tolerance of rice to long-term stagnant flooding that submerges most of the shoot will aid in breeding tolerant cultivars. AoB Plants 6: plu055; DOI: 10.1093/aobpla/plu055.

Voesenek LA, Bailey-Serres J. 2013. Flooding tolerance: $\mathrm{O}_{2}$ sensing and survival strategies. Curr Opin Plant Biol 16: 647-53.

Yoshida S, Forno D, Cock J, Gomez KA. 1976. Laboratory manual for physiological studies of rice. IRRI. Los Banos, Philipines. 